\title{
BADANIA WYBRANYCH WSKAŹNIKÓW SKRAWALNOŚCI PODCZAS FREZOWANIA STOPU INCONEL 718 NARZĘDZIAMI CERAMICZNYMI
}

\begin{abstract}
W artykule przedstawiono wyniki badań momentu skrawania i chropowatości powierzchni w procesie frezowania czołowego stopu niklu Inconel 718. W eksperymencie wykorzystano narzędzia monolityczne o średnicy $d=12 \mathrm{~mm}$, wykonane $\mathrm{z}$ ceramiki SIALON. Badania przeprowadzono przy zmiennych parametrach technologicznych: $a_{p}=0,8-1,2 \mathrm{~mm}, v_{c}=400-898 \mathrm{~m} / \mathrm{min}, f_{z}=0,07-0,16 \mathrm{~mm} /$ ostrze. Zauważono, że wzrost posuwu na ostrze $f_{z}$ i głębokości skrawania $a_{p}$ powoduje większe wartości momentu skrawania $M_{c}$. W zakresie $v_{c}=400-732 \mathrm{~m} / \mathrm{min}$ następuje spadek wartości momentu skrawania $M_{c}$. Parametry chropowatości powierzchni również zależą od warunków obróbki.
\end{abstract}

Słowa kluczowe: ceramika SIALON, frezowanie, Inconel 718, chropowatość powierzchni, moment skrawania

\section{Wprowadzenie}

W przemyśle lotniczym na konstrukcje silników lotniczych czy zespołów statków powietrznych z powodzeniem są stosowane trudnoobrabialne materiały, takie jak stal nierdzewna, stopy tytanu czy stopy niklu [8]. Stopy niklu są wykorzystywane w lotnictwie od lat 60 . ubiegłego wieku, co było spowodowane intensywnym rozwojem metalurgii tej grupy materiałów. Produkuje się je głównie w postaci blach walcowanych, prętów, odlewów precyzyjnych, odkuwek, co umożliwia zastosowanie ich na elementy maszyn, gdzie najbardziej istotną rolę odgrywa żarowytrzymałość i żaroodporność. Stopy niklu znajdują zastosowanie zwłaszcza do budowy komór spalania oraz turbin i wylotów spalin. Najczęściej stosowanymi gatunkami stopów niklu są materiały z grup Inconel, Nimonic, Udimet [5].

\footnotetext{
1 Autor do korespondencji/corresponding author: Agnieszka Skoczylas, Politechnika Lubelska, ul. Nadbystrzycka 36, 20-618 Lublin, tel.: 8153 4707, e-mail: a.skoczylas@pollub.pl

${ }^{2}$ Kazimierz Zaleski, Politechnika Lubelska, e-mail: k.zaleski@ pollub.pl
} 
Jednym z dominujących stopów niklu na rynku lotniczym jest stop Inconel 718 , który stanowi ponad połowę wszystkich superstopów używanych do budowy silników [5]. Inconel 718 to utwardzany wydzieleniowo stop niklu o doskonałej odporności na korozję w wielu mediach, odporności na pełzanie, podatności na kucie i odlewanie oraz o dobrej spawalności $[5,13]$. Wyjątkowe właściwości stopu Inconel 718 sprawiają, że należy on do materiałów trudnoobrabialnych. Zawartość twardych faz węglikowych w strukturze krystalicznej przyspiesza zużywanie się ostrza podczas obróbki. Niska przewodność cieplna utrudnia odprowadzanie ciepła ze strefy obróbki, a wysoka wytrzymałość na rozciąganie uniemożliwia stosowanie dużych głębokości skrawania $[4,6,12]$. Ze względu na swoje specyficzne właściwości obróbka stopu niklu Inconel 718 wymaga odpowiedniego doboru parametrów i warunków technologicznych oraz materiału narzędziowego.

Prędkość skrawania wpływa istotnie na przebieg obróbki i jakość powierzchni obrobionej. Wzrost prędkości skrawania prowadzi do spadku chropowatości powierzchni do pewnej wartości minimalnej [13, 16], a z drugiej strony powoduje wzrost temperatury skrawania oraz intensywne zużywanie się powierzchni przyłożenia narzędzia, co może powodować pogorszenie jakości powierzchni $[13,16]$. Mechanizmami zużycia ostrza dominującymi podczas frezowania szybkościowego stopu Inconel 718 są: ścieranie, adhezja, łuszczenie oraz mikropęknięcia [13]. Składowe całkowitej siły skrawania zależą od parametrów technologicznych obróbki. Wzrost prędkości skrawania przekłada się na spadek wartości siły, przy czym po przekroczeniu wartości minimalnej następuje jej wzrost. Wiąże się to z występowaniem zjawiska „przywierania” wiórów do powierzchni obrabianej, a tym samym wzrostem objętości materiału akumulującego ciepło $[3,10]$.

Autorzy publikacji [13] analizowali wpływ prędkości skrawania na siły skrawania. Najmniejsze wartości siły zostały uzyskane dla prędkości $v_{c}$ powyżej $1000 \mathrm{~m} / \mathrm{min}$. W pracy [16] badano wpływ prędkości skrawania i materiału ostrza na wartość siły wypadkowej. W badaniach zastosowano płytki z różnych materiałów ceramicznych. Zauważono, że wraz ze wzrostem prędkości $v_{c} \mathrm{~W}$ zakresie $500-900 \mathrm{~m} / \mathrm{min}$ siła spada, natomiast po przekroczeniu $v_{c}=900 \mathrm{~m} / \mathrm{min}$ wartość siły zaczyna gwałtownie rosnąć.

Alauddin i inni [1] w swojej pracy badali wpływ głębokości skrawania i posuwu na wartość składowych sił skrawania. Autorzy zauważyli, że wzrost analizowanych parametrów technologicznych powoduje wzrost obciążenia ostrza skrawającego, co prowadzi do większych wartości składowych sił skrawania.

Zastosowanie chłodzenia i smarowania w postaci zalewowej lub metodami MQL (Minimum Quantity Lubrication) oraz MQCL (Minimum Quantity Cooling Lubrication) podczas obróbki powoduje wzrost trwałości ostrza. Wykorzystując metodę MQCL, uzyskuje się zmniejszenie siły przy skrawaniu, co jest spowodowane mniejszym tarciem w układzie narzędzie - wiór oraz narzędzie - przedmiot obrabiany [15]. 
Poza parametrami technologicznymi na przebieg procesu obróbki stopu Inconel 718 wpływa rodzaj i geometria ostrza. Według autorów pracy [11] do obróbki z wysokimi prędkościami skrawania są zalecane ceramiczne płytki o ujemnym kącie natarcia lub ceramiczne okrągłe płytki z powłoką naniesioną metodą PVD. Zastosowanie płytek węglikowych, z powłoką lub bez powłoki, oraz narzędzi jednolitych $\mathrm{z}$ węglików spiekanych do obróbki stopu niklu wiąże się z koniecznością stosowania prędkości skrawania z zakresu od $24 \mathrm{~m} / \mathrm{min}$ do $100 \mathrm{~m} / \mathrm{min}[1,7,9,15]$ oraz niewielkich przekrojów warstwy skrawanej $a_{p}=0,3-2,0 \mathrm{~mm}$ i $f_{z}=0,04-0,16 \mathrm{~mm} /$ ostrze $[1-3,13]$.

Wiele publikacji wykazuje $[8,13,16]$, że wydajną i efektywną obróbkę stopu Inconel 718 można przeprowadzić, stosując okrągłe płytki ceramiczne, przy czym konieczne są wysokie prędkości skrawania z zakresu $v_{c}=500-3000 \mathrm{~m} / \mathrm{min}$. Słabą stroną wykorzystania okrągłych płytek, ze względu na wysokie prędkości skrawania, do obróbki stopów niklu jest powstawanie naprężeń w warstwie wierzchniej (niedopuszczalnych w przypadku części lotniczych), które są naprężeniami rozciągającymi. Stanowi to ograniczenie wykorzystania tej odmiany płytek skrawających.

Na podstawie przeprowadzonego przeglądu literatury należy zauważyć, że brak jest opracowań, które przedstawiałyby wykorzystanie frezów trzpieniowych jednolitych, wykonanych z materiałów ceramicznych, do obróbki stopów niklu. Obecnie stosuje się narzędzia składane z okrągłymi płytkami. Za zasadne uznano zatem przeprowadzenie badań wpływu parametrów technologicznych frezowania stopu Inconel 718 jednolitymi frezami ceramicznymi na wartość momentu skrawania $M_{c}$ oraz parametry chropowatości powierzchni.

\section{Metodyka badań}

W badaniach zastosowano prostopadłościenne próbki ze stopu niklu Inconel 718, którego skład chemiczny i wybrane właściwości przedstawiono w tab. 1. Próby frezowania czołowego zostały przeprowadzone na pionowym centrum frezarskim Avia VMC 800 HS, znajdującym się w Katedrze Podstaw Inżynierii Produkcji Politechniki Lubelskiej. Jako narzędzia użyto frezów czteroostrzowych jednolitych firmy Mitsubishi (oznaczenie C: 4SRBD1200R150) o średnicy $d=12 \mathrm{~mm}$ z promienieniem zaokrąglenia naroża $r_{\varepsilon}=1,5 \mathrm{~mm}$. Narzędzia były wykonane z ceramiki SIALON. Proces frezowania współbieżnego był realizowany na sucho.

Proces obróbki został zrealizowany dla następujących parametrów technologicznych:

- prędkość skrawania $v_{c}=400-893 \mathrm{~m} / \mathrm{min}$,

- prędkość posuwu $v_{f}=5440-12433 \mathrm{~mm} / \mathrm{min}$,

- głębokość skrawania $a_{p}=0,8-2 \mathrm{~mm}$,

- szerokość frezowania $a_{e}=7 \mathrm{~mm}$. 
Tabela 1. Skład chemiczny i wybrane właściwości stopu niklu Inconel 718 [5]

Table 1. Chemical composition and selected properties of nickel-based alloy Inconel 718 [5]

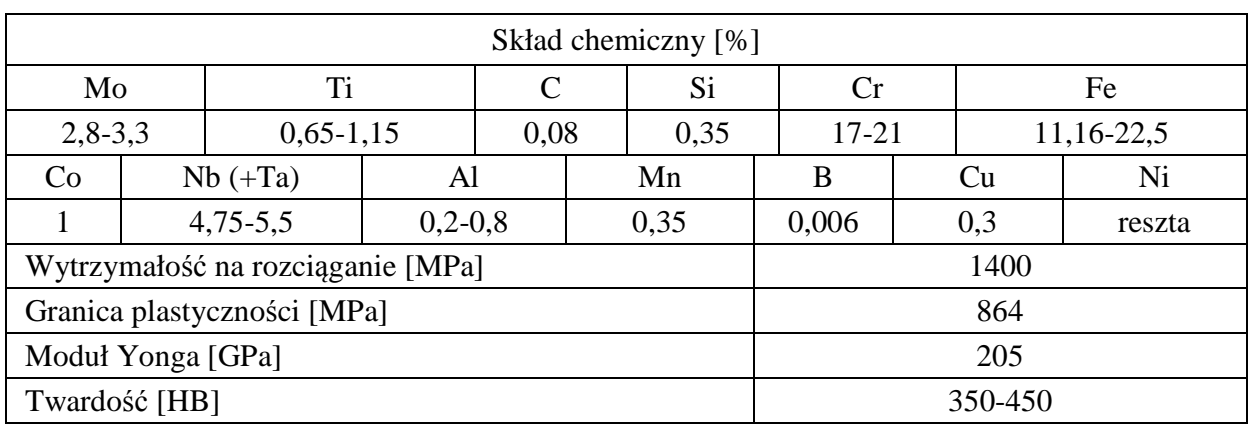

Pomiar momentu skrawania $M_{c}$ przeprowadzono za pomocą siłomierza obrotowego Kistler 9125A, który był zestawiony w torze pomiarowym ze wzmacniaczem 5237A1/A2 oraz modułem do akwizycji danych pomiarowych DAQ 5697A. Siłomierz pracował w maksymalnym zakresie pomiarowym przy momencie skrawania równym $\pm 50 \mathrm{Nm}$.

Pomiary chropowatości powierzchni i topografii 3D wykonano za pomocą urządzenia T8000RC 120-140 firmy Hommel-Etamic.

\section{Wyniki badań}

Opierając się na przebiegach czasowych momentu skrawania, sporządzono wykresy ilustrujące wpływ parametrów technologicznych na badaną zmienną. $\mathrm{Na}$ rysunku 1 przedstawiono wpływ prędkości skrawania na moment skrawania $M_{c}$. Analizując uzyskane wyniki, można zauważyć, że w zakresie $v_{c}=400-732 \mathrm{~m} / \mathrm{min}$ następuje spadek momentu skrawania. Jest to związane $\mathrm{z}$ prawdopodobnym wzrostem temperatury $\mathrm{w}$ strefie ścinania, co prowadzi do obniżenia twardości materiału i wytrzymałości w tej strefie [13]. Tymczasem narzędzie ceramiczne pozostaje stabilne i zachowuje swoje zdolności skrawne mimo podwyższonej temperatury, co umożliwia realizację ,poprawnej” pracy skrawania [14].

Przy prędkości skrawania z przedziału $v_{c}=732-893 \mathrm{~m} / \mathrm{min}$ następuje niewielki wzrost momentu skrawania, prawdopodobnie z powodu wzrostu temperatury w strefie skrawania, co przekłada się na wzrost zużycia ostrza [16]. Jak wiadomo [8], obróbka płytką zużytą generuje większe wartości składowych siły skrawania, co wpływa na większy moment skrawania $M_{c}$. Wzrost prędkości posuwu oraz głębokości skrawania przekłada się na większe wartości momentu skrawania $M_{c}$ (rys. 2 i 3 ). Większe wartości posuwu na ostrze $f_{z}$ oraz głębokości skrawania $a_{p}$ powodują zwiększenie pola poprzecznego przekroju warstwy skrawanej, co przekłada się na wartość siły, a tym samym momentu skrawania $M_{c}$. 


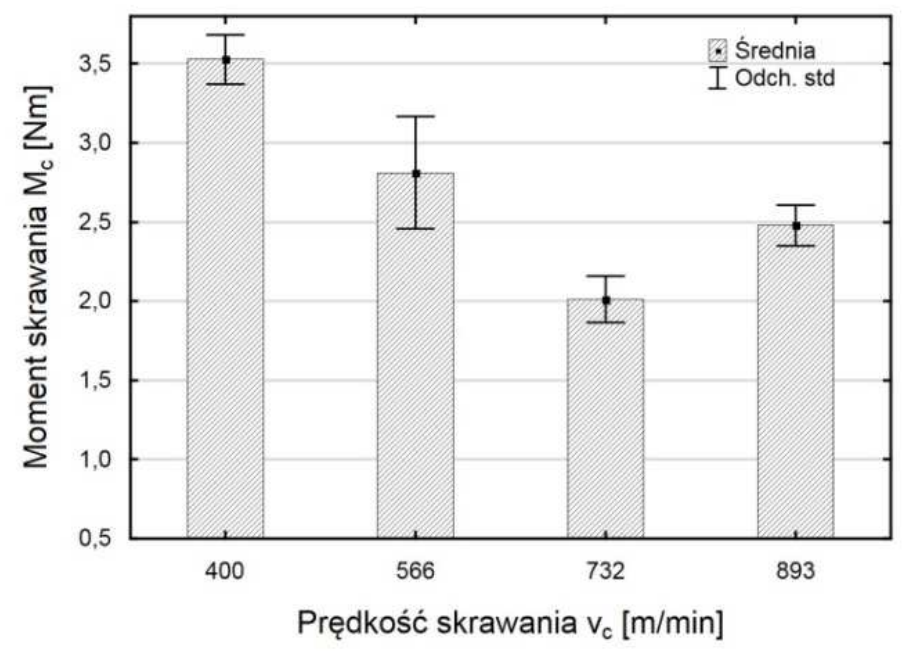

Rys. 1. Wpływ prędkości skrawania $v_{c}$ na moment skrawania $M_{c}$ $\left(v_{f}=7771 \mathrm{~mm} / \mathrm{min}, a_{p}=1,2 \mathrm{~mm}\right)$

Fig. 1. Effect of cutting speed $v_{c}$ on cutting torque $M_{c}\left(v_{f}=7771\right.$ $\mathrm{mm} / \mathrm{min}, a_{p}=1.2 \mathrm{~mm}$ )

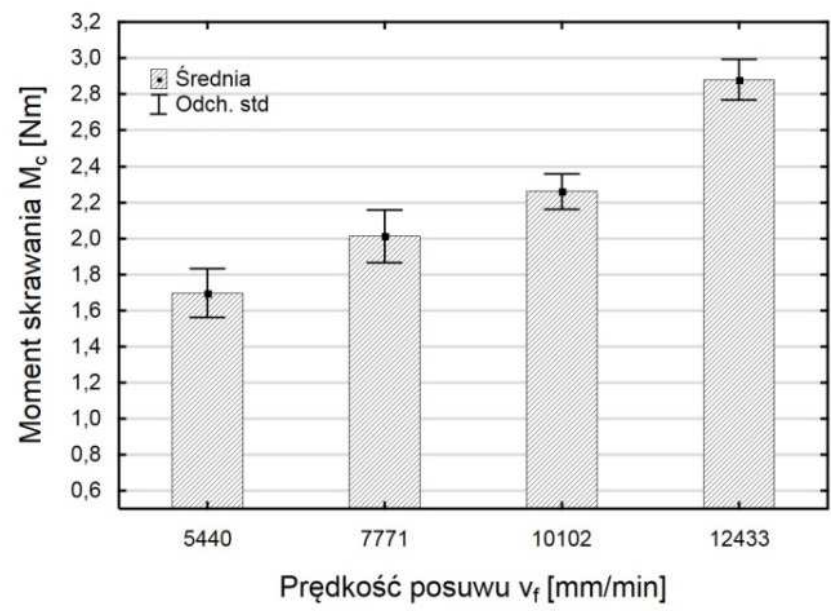

Rys. 2. Wpływ prędkości posuwu $v_{f}$ na moment skrawania $M_{c}$ $\left(v_{c}=732 \mathrm{~m} / \mathrm{min}, a_{p}=1,2 \mathrm{~mm}\right)$

Fig. 2. Effect of feed rate $v_{f}$ on cutting torque $M_{c}\left(v_{c}=732 \mathrm{~m} / \mathrm{min}\right.$, $\left.a_{p}=1.2 \mathrm{~mm}\right)$

Dla momentu skrawania $M_{c}$ (rys. 3) uzyskano prawie liniowy wzrost w funkcji głębokości skrawania. Wzrost głębokość skrawania powoduje, że każde ostrze narzędzia usuwa coraz większą ilość materiału, co skutkuje większym oporem ze strony materiału obrabianego. 


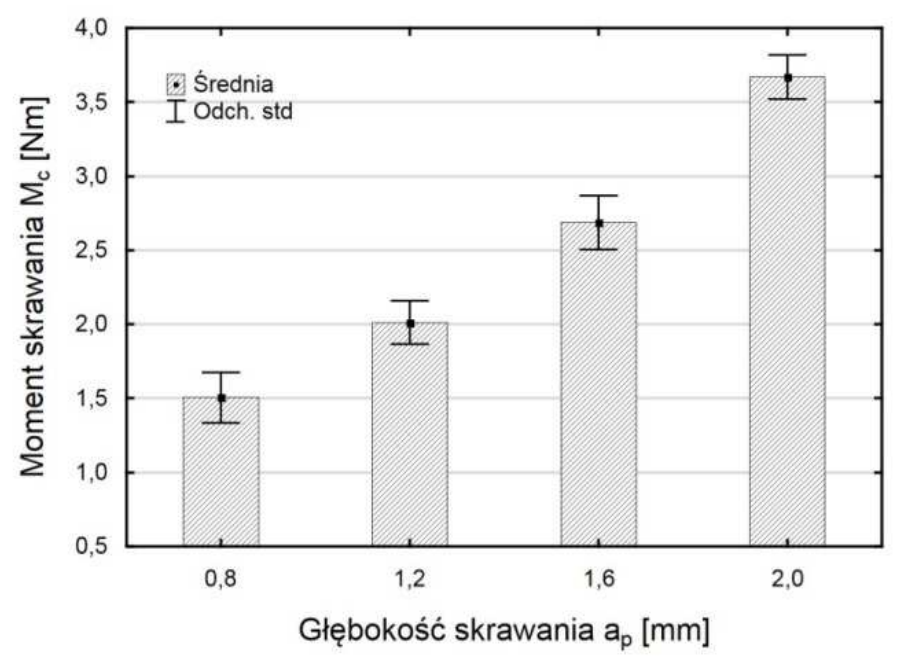

Rys. 3. Wpływ głębokości skrawania $a_{p}$ na moment skrawania $M_{c}$ $\left(v_{c}=732 \mathrm{~m} / \mathrm{min}, v_{f}=7771 \mathrm{~mm} / \mathrm{min}\right)$

Fig. 3. Effect of deep of cut $a_{p}$ on cutting torque $M_{c}\left(v_{c}=732 \mathrm{~m} / \mathrm{min}\right.$, $\left.v_{f}=7771 \mathrm{~mm} / \mathrm{min}\right)$

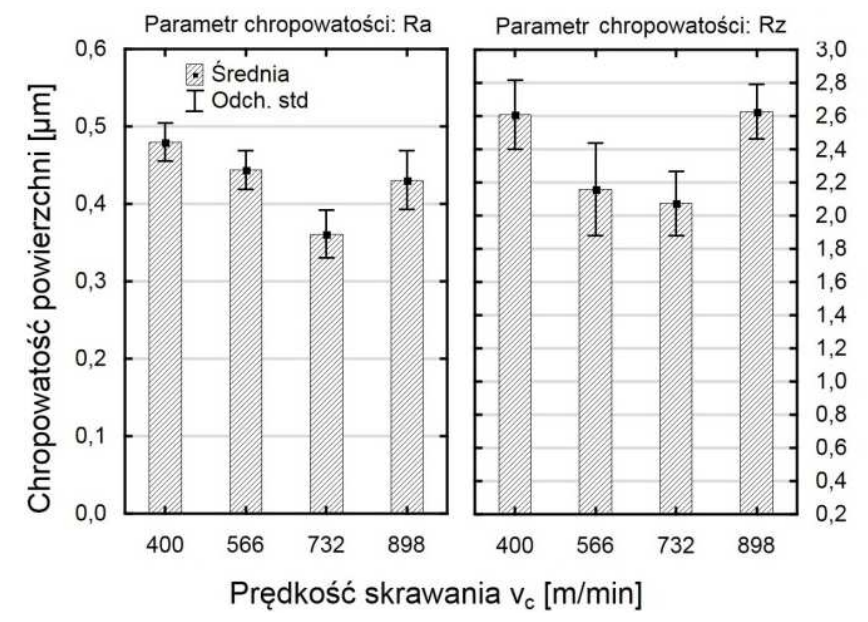

Rys. 4. Wpływ prędkości skrawania na parametry chropowatości powierzchni $R a$ i $R z\left(v_{f}=7771 \mathrm{~mm} / \mathrm{min}, a_{p}=1,2 \mathrm{~mm}\right)$

Fig. 4. Effect of cutting speed on surface roughness parameters $R a$ and $R z\left(v_{f}=7771 \mathrm{~mm} / \mathrm{min}, a_{p}=1.2 \mathrm{~mm}\right)$

Wyniki badań wskazują, że parametry technologiczne wpływają na chropowatość powierzchni. Rysunek 4 przedstawia wpływ prędkości skrawania na parametry chropowatości $R a$ i $R z$. Analizując wpływ $v_{c}$ na chropowatość powierzchni, można zauważyć, że w zakresie $v_{c}=400-732 \mathrm{~m} / \mathrm{min}$ następuje spadek 
chropowatości powierzchni. Może to być spowodowane występowaniem mniejszych wibracji układu obróbkowego dla mniejszych wartości sił, co przekłada się na mniejszą chropowatość powierzchni. Po przekroczeniu prędkości skrawania $v_{c}=732 \mathrm{~m} / \mathrm{min}$ parametry chropowatości powierzchni zaczynają rosnąć. Uzyskany rozkład parametrów chropowatości powierzchni $R a$ i $R z$ w funkcji prędkości skrawania jest zbieżny z wynikami pracy [16].

Wzrost wartości posuwu na ostrze powoduje powstawanie śladów mikronierówności w większych odległościach, co zwiększa chropowatość powierzchni (rys. 5). W zakresie prędkości posuwu $v_{f}=5440-7771 \mathrm{~mm} / \mathrm{min}$ brak jest jednoznacznego wpływu analizowanego parametru technologicznego na parametr chropowatości powierzchni $R a$. Prawdopodobnie zaistniałe zjawisko wiąże się z dużymi odkształceniami sprężystymi materiału obrabianego dla danego zakresu prędkości posuwu. Na rysunku 6 przedstawiono wpływ głębokości skrawania na parametry chropowatości powierzchni $R a$ i $R z$. Zgodnie z przypuszczeniem wzrost $a_{p}$ powoduje większe wartości chropowatości powierzchni. Podczas obróbki z większą głębokością skrawania wzrasta moment skrawania, co przekłada się na parametry chropowatości $R a$ i $R z$. Rozważając topografię powierzchni po frezowaniu stopu Inconel 718 (rys. 7), niezależnie od warunków obróbki na powierzchni obrabianej występuje odwzorowanie zarysu pracy ostrzy. Na powierzchni obrabianej występują mikronierówności o układzie promieniowym, z wyraźnie widocznymi ostrymi zagłębieniami i wzniesieniami.

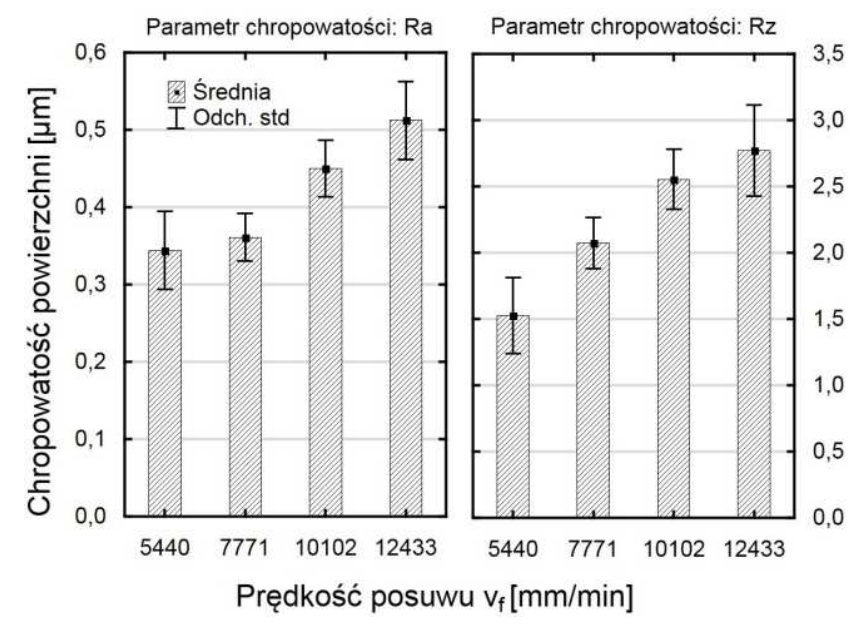

Rys. 5. Wpływ prędkości posuwu na parametry chropowatości powierzchni $R a$ i $R z\left(v_{c}=732 \mathrm{~m} / \mathrm{min}, a_{p}=1,2 \mathrm{~mm}\right)$

Fig. 8. Effect of feed rate on surface roughness parameters $R a$ and $R z\left(v_{c}=732 \mathrm{~m} / \mathrm{min}, a_{p}=1.2 \mathrm{~mm}\right)$ 




Rys. 6. Wpływ głębokości skrawania na parametry chropowatości powierzchni $R a$ i $R z\left(v_{c}=732\right.$ $\mathrm{m} / \mathrm{min}, v_{f}=7771 \mathrm{~m} / \mathrm{min}$ )

Fig. 6. Effect of deep of cut on surface roughness parameters $R a$ and $R z\left(v_{c}=732 \mathrm{~m} / \mathrm{min}, v_{f}=7771\right.$ $\mathrm{m} / \mathrm{min}$ )



$$
\begin{aligned}
& \mathrm{Sa}=0,368 \mu \mathrm{m}, \\
& \mathrm{Sz}=3,13 \mu \mathrm{m}, \\
& \mathrm{Sp}=1,98 \mu \mathrm{m}, \\
& \mathrm{Sv}=1,15 \mu \mathrm{m}
\end{aligned}
$$

Rys. 7. Topografia powierzchni stopu Inconel 718 po frezowaniu $\left(v_{c}=732 \mathrm{~m} / \mathrm{min}, a_{p}=1,2 \mathrm{~mm}, v_{f}=7771 \mathrm{~mm} / \mathrm{min}\right)$

Fig. 7. Surface topography of the Inconel 718 alloy after milling $\left(v_{c}=732 \mathrm{~m} / \mathrm{min}, a_{p}=1.2 \mathrm{~mm}, v_{f}=7771 \mathrm{~mm} / \mathrm{min}\right)$

\section{Podsumowanie}

W pracy analizowano wpływ parametrów technologicznych na moment skrawania $M_{c}$ oraz parametry chropowatości powierzchni podczas frezowania stopu Inconel 718. Natępujące wnioski podsumowują rezultaty przeprowadzonych badan:

- wzrost prędkości skrawania $\mathrm{w}$ zakresie $v_{c}=400-732 \mathrm{~m} / \mathrm{min}$ powoduje spadek momentu skrawania $M_{c}$ oraz parametrów chropowatości powierzchni,

- wzrost głębokości skrawania $a_{p}$ i posuwu na ostrze $f_{z}$ powoduje wzrost momentu skrawania $M_{c}$ i chropowatości powierzchni, 
- zależności obrazujące wpływ parametrów frezowania stopu Inconel 718 frezami monolitycznymi ze SIALON-u mają charakter zbieżny do przebiegu tych zależności w procesie frezowania frezami składanymi z płytkami ceramicznymi $[13,16]$.

Wybór frezów jednolitych wykonanych z ceramiki do frezowania stopu Inconel 718 jest podyktowany koniecznością wykorzystania takich narzędzi (o mniejszych średnicach) do wykonywania rowków oraz tzw. „kieszeni”" $\mathrm{w}$ elementach $\mathrm{z}$ tego trudno orbrabialnego materiału. Narzędzia składane z okrągłymi płytkami ceramicznymi pozwalają wprawdzie na efektywną obróbkę stopu Inconel 718, z drugiej strony jednak posiadają pewne ograniczenia $\mathrm{w}$ ich wykorzystaniu [13]. Uzyskane wykniki badań wybranych wskaźników skrawalności pokazują, że z powodzeniem można stosować narzędzia monolityczne ceramiczne do obróbki stopu Inconel 718.

\section{Literatura}

[1] Alauddin A., Mazid M.A., El Baradi M.A., Hashmi M.S.J.: Cutting forces in the end milling of Inconel 718, J. Mat. Proc. Technol., 77 (1998) 153-159.

[2] Bławucki S., Matuszak J., Zaleski K.: Badania porównawcze wskaźników skrawalności w procesie frezowania stopów niklu Inconel 625 i Inconel 718, Mechanik, 88 (2015) 293-301.

[3] Bławucki S., Zaleski K., Matuszak J.: Badania sił skrawania podczas frezowania superstopu Inconel 718 z podwyższoną prędkością skrawania, Mechanik, 89 (2016) 1090-1091.

[4] Devillez A., Le Coz G., Dominiak S., Dudzinski D.: Dry machining of Inconel 718, workpiece surface integrity, Journal of Materials Processing Technology, 211 (2011) 1590-1598.

[5] Dul I.: Zastosowanie i przetwarzanie stopów niklu w przemyśle lotniczym, Przegląd Spawalnictwa, 7-8 (2009) 67-73.

[6] Ezugwu E.O., Wang Z.M., Machado A.R.: The machinability of nickel-based alloys: a review, Journal of Materials Processing Technology, 86 (1999) 1-16.

[7] Kaya B., Oysu C., Ertunc H.M.: Force-torque based on-line tool wear estimation system for CNC milling of Inconel 718 using neural networks, Advances in Engineering Software, 42 (2011) 76-84.

[8] Kossakowska J., Siemiątkowski Z., Jemielniak K.: Badania zależności sił skrawania od stanu narzędzia i parametrów skrawania podczas frezowania zgrubnego Inconelu 718 płytkami ceramicznymi, Mechanik, 8-9 (2015) 797-805.

[9] Krain H.R., Sharman A.R., Ridgway K.: Optimisation of tool life and productivity when end milling Inconel 718TM, Journal of Materials Processing Technology, 189 (2007) 153-161.

[10] Liao Y.S., Lin H.M., Wang J.H.: Behaviors of end milling Inconel 718 superalloy by cemented carbide tools, Journal of Materials Processing Technology, 201 (2008) 460-465. 
[11] Li L., He N., Wang M., Wang Z.G.: High speed cutting of Inconel 718 with coated carbide and ceramic inserts, Journal of Materials Processing Technology, 129 (2002) 127-130.

[12] Rahman M., Seah W.K.H., Teo T.T.: The Machinability of Incone1 718, Journal of Materials Processing Technology, 63 (1997) 199-204.

[13] Tian X., Zhao J., Zhao J., Gong Z., Dong Y.: Effect of cutting speed on cutting forces and wear mechanisms in high-speed face milling of Inconel 718 with Sialon ceramic tools, International Journal Advances Manufacturing Technology, 69 (2013) 2669-2678.

[14] Vagnorius Z., Sørby K.: Effect of high-pressure cooling on life of SiAlON tools in machining of Inconel 718, International Journal of Advanced Manufacturing Technology, 54 (2011) 83-92.

[15] Zhang S., Li J.F., Wang Y.W.: Tool life and cutting forces in end milling Inconel 718 under dry and minimum quantity cooling lubrication cutting conditions, Journal of Cleaner Production, 32 (2012) 81-87.

[16] Zheng G., Zhao J., Zhou Y., Lui X., Tian X.: Performance of graded nano-composite ceramic tools in ultra-high-speed milling of Inconel 718, International Journal of Advanced Manufacturing Technology, 67 (2013) 2799-2810.

\title{
INVESTIGATIONS OF SELECTED MACHINABILITY INDICATORS IN THE MILLING OF INCONEL 718 ALLOY USING CERAMIC TOOLS
}

\begin{abstract}
S u m m a r y
This paper presents the results of an investigation of the cutting torque and surface roughness in the face milling of nickel-based alloy Inconel 718. In the experimental tests monolithic tools with a diameter of $d=12 \mathrm{~mm}$ made of SIALON ceramics were used. The tests were conducted at variable technological parameters: $a_{p}=0.8-2 \mathrm{~mm} ; v_{c}=400-893 \mathrm{~m} / \mathrm{min} ; f_{z}=0.07-0.16 \mathrm{~mm} / \mathrm{per}$ tooth. It has been found that increasing the feed per tooth $f_{z}$ and the depth of cut $a_{p}$ resulted in a higher cutting torque. In the range of $v_{c}=400-732 \mathrm{~m} / \mathrm{min}$ the decrease of cutting torque $M_{c}$ was observed. Surface roughness parameters also depended on machining conditions.
\end{abstract}

Keywords: SIALON ceramics, milling, Inconel 718, surface roughness, cutting torque

DOI: $10.7862 / \mathrm{rm} .2017 .33$

Otrzymano/received:12.07.2017

Zaakceptowano/accepted: 27.09.2017 